PACS numbers: 05.60.Gg, 73.40.Gk, 73.63.Nm, 81.07.Nb, 85.65.+h

\title{
Barrier and Superexchange Models for the Analysis of Tunnelling Current in Molecular Junctions 'Metal-Molecular Wire-Metal'
}

\author{
E. G. Petrov
}

\author{
Bogolyubov Institute for Theoretical Physics, N.A.S. of Ukraine, \\ $14^{\underline{b}}$, Metrologichna Str., \\ UA-03143 Kyiv, Ukraine
}

Based on the modified superexchange model, analytical expressions are obtained, which are convenient for analysing the tunnelling current through a molecular wire consisting of a regular chain connected to the electrodes by terminal groups. An ohmic tunnelling regime is considered, in which the terminal groups act as contact barriers, and the interaction of the chain with the electrodes is parameterized in the width factors. Analytical expressions for the current show that, for certain ratios between the key superexchange parameters, these expressions coincide in form with the expressions for the current obtained within the framework of the barrier model and the standard superexchange model, thereby showing the applicability conditions of these models. Thus, the barrier model can be used to analyse the current-voltage characteristics of the molecular wire in the presence of strongly delocalized molecular chain orbitals, whereas the standard superexchange model works with strong localization of molecular orbitals, i.e., with 'deep' tunnelling. The modified superexchange model also shows that a purely exponential current drop with increasing chain units appears, starting from a certain chain length, and depends significantly on the magnitude of the attenuation factor. An illustration of the results is for chains consisting of one-site and two-site repeating units. For such chains, in addition to the expressions for attenuation coefficients, formulas for preexponential factors are obtained, and it is shown that the estimation of the contact current by approximating the current-voltage characteristics of the wire to the possible value of the current at zero chain length is physically unjustified. For estimates of contact current, the minimum internal wire length must include two structural units of the chain.

Із використанням модифікованого суперобмінного моделю одержано аналітичні вирази, які є зручними для аналізи тунельного струму через молекулярний провід, що складається з регулярного ланцюжка, з'єднаного з електродами кінцевими групами. Розглядається режим омічного тунелювання, в якому кінцеві групи працюють як контактні бар’єри, а взає- 
модія ланцюжка з електродами параметризується з врахуванням коефіцієнтів ширини. Аналітичні вирази для струму показують, що за певних співвідношень між ключовими суперобмінними параметрами ці вирази збігаються за формою з виразами для струму, які можна одержати в рамках бар'єрного моделю та стандартного суперобмінного моделю. Таким чином показано умови застосовности двох останніх моделів. Так, бар'єрний модель може використовуватися для аналізи вольт-амперних характеристик молекулярного проводу за наявности сильно делокалізованих молекулярних орбіталей ланцюжка, у той час як стандартний суперобмінний модель працює за сильної локалізації молекулярних орбіталей, тобто за «глибокого» тунелювання. Модифікований суперобмінний модель демонструє також, що чисто експоненційне спадання струму із збільшенням кількости ланок ланцюжка з'являється, починаючи з певної довжини ланцюжка, й істотно залежить від величини фактора згасання. Ілюстрацію результатів проведено для ланцюжків, які складаються 3 одноцентрових і двоцентрових одиниць, що повторюються. Для таких ланцюжків, окрім виразів для коефіцієнтів згасання, одержано формули для передекспоненційних факторів і показано, що оцінка контактного струму шляхом апроксимації вольт-амперної характеристики проводу до можливого значення струму за нульової довжини ланцюжка фізично невиправдана. Для оцінок контактного струму мінімальна внутрішня довжина проводу має містити дві структурні одиниці ланцюжка.

Key words: electronic transport, tunnelling, molecular wire, superexchange, non-resonant current.

Ключові слова: електронний транспорт, тунелювання, молекулярний провід, суперобмін, нерезонансний струм.

(Received 4 December, 2019)

\section{INTRODUCTION}

One of the important problems of molecular electronics is to elucidate the mechanisms of formation of current through individual molecules and molecular nanostructures [1-4]. Among the latter, a special role belongs to molecular wires, which carry out the distant transport of charges (electrons/holes) in devices capable of performing the functions of the basic elements of molecular electronics [5-7]. Molecular wires are chains of repeating monomers (structural units of a regular chain) and terminal groups, through which the wire establishes the communication between the functional elements of the circuit or metal contacts. Studies carried out using scanning tunnelling and atomic force microscopes showed that in the ohmic regime of charge transmission the current through the molecular wire is formed mainly due to the electron/hole tunnelling. The experiment shows an exponential current drop with increasing the length of the interior part of the wire. 
This drop is well described by the expression [8-11]

$$
I=I_{c} e^{-\beta d},
$$

where $d$ (in $\AA$ ) is the tunnelling length. The current attenuation factor $\beta$ (in $\AA^{-1}$ ) characterizes the structural and energy characteristics of the regular chain, and the value $I_{c}$ is associated with the injection (contact) current, which is often estimated using the approximation $I_{c}=I_{\mid \lim d \rightarrow 0}$. Analytical expressions for $\beta$ and $I_{c}$ are obtained in the framework of a particular physical model of charges tunnelling in a system 'electrode $L$-molecular wire-electrode $R$ ' (LMR junction). The most popular are the Simmons model of electron tunnelling through a rectangular barrier and the McConnel superexchange model [12, 13] (see the use of models, for example, in [9, 11, 14-16]). Recently, a modified superexchange model of tunnelling transmission has been proposed, from which the expressions for the attenuation factors obtained in the framework of the Simmons and McConnel models follow as special cases $[17,18]$.

In this work, we compare the expressions for the factors $\beta$ and $I_{c}$, obtained within the framework of the above models and find the conditions for the applicability of the models to describe the currentvoltage characteristics of molecular wires under the ohmic regime of charge transmission.

\section{THEORETICAL MODELS}

Each model leads to expression for the factors $\beta$ and $I_{c}$, which contain a certain set of parameters that reflect the structural and energy characteristics of the LMR junction.

\subsection{Flat-Barrier Simmons Model}

The model uses three main parameters: the barrier height $\Delta E$, the barrier width $d$ (Fig. 1) and the effective tunnelling mass $m^{*}$. In the case of Ohm regime, which works under the condition

$$
|e V| \ll \Delta E,
$$

where $V$ is the voltage bias and $e=-|e|$ is the electron charge, using the Simmons model [12] leads to the expression for current density $J=v I$ where $v$ is the number of wires that come in contact with the surface area, through which current actually passes. (In selfassembled monolayers, $v$ is about $(4-5) \cdot 10^{14}$ wires per $\mathrm{cm}^{2}[9]$.) The cur- 

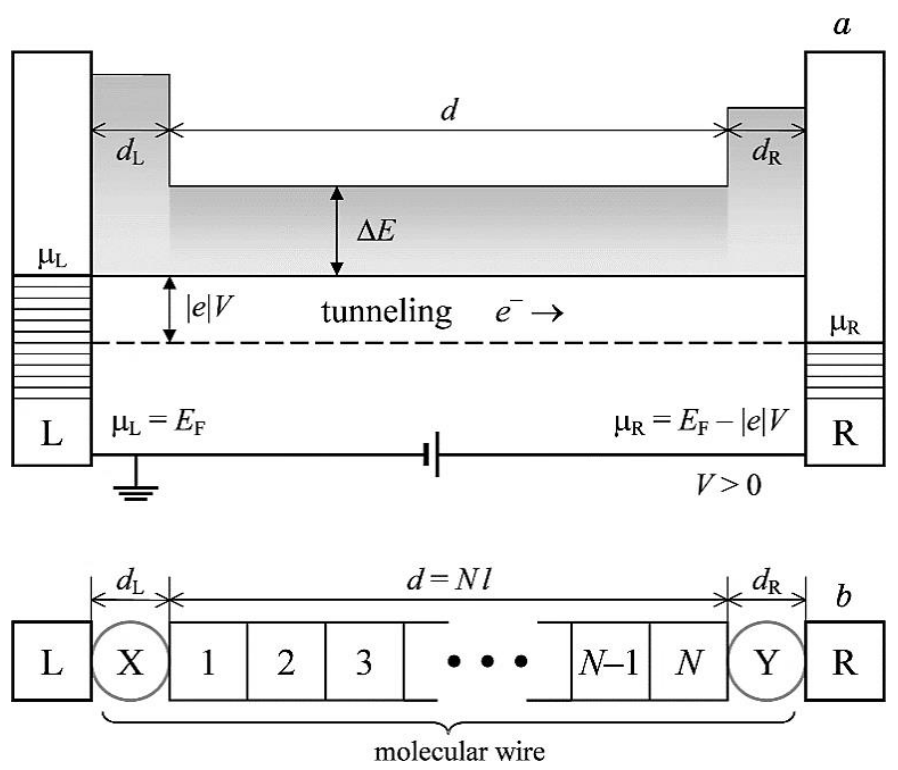

Fig. 1. Energy $(a)$ and structural $(b)$ schemes for electron tunnelling through a terminated molecular wire of length $\mathrm{C}$ in the barrier model. An electron tunnels from the left electrode to the right one with energy arranged in the $\left[\mu_{L}, \mu_{R}\right]$ energy window. The height and width of the interior tunnel barrier are $d=N l$ and $\Delta E$, respectively. The terminal units of wire $X$ and $Y$ create contact barriers with the corresponding widths $d_{L}$ and $d_{R}$.

rent across a single molecular wire appears in the form (1) where the current drop is characterized by the attenuation factor

$$
\beta=\beta_{B R}=(2 / \hbar) \sqrt{2 m^{*} \Delta E},
$$

whereas the pre-exponential factor reads

$$
I_{c}=\left(\frac{V}{d}\right) \frac{e^{2} \sqrt{2 m^{*} \Delta E}}{4 \pi^{2} \hbar^{2}} .
$$

We see, however, that $\lim _{d \rightarrow 0} I_{c}=\infty$ and, therefore, from the physical point of view, the $I_{c}$ cannot be identified with the injection current. Thus, a simple flat-barrier model does not work in the contact region. It cannot also be used to evaluate the near zero bias contact conductance $G_{c}=\left.\left(\partial I_{c} / \partial V\right)\right|_{V \rightarrow 0}$.

A more accurate application of the flat-barrier model implies the presence of contact areas formed by the terminal units of the molecular wire. In this case, the left (right) terminal unit is considered as a rec- 
tangular barrier spacer with a width $d_{L}\left(d_{R}\right)(c f$. Fig. 1). Consequently, at the ohmic tunnelling regime, the pre-exponential factor in the Eq. (1) can be represented as

$$
I_{c}=V A e^{-\beta_{L} d_{L}} e^{-\beta R^{d} R},
$$

where $A$ is the constant, whereas $\beta_{L}$ and $\beta_{R}$ are the hypothetical decay parameters [9].

Despite the fact that the flat-barrier model describes the exponential drop in the tunnelling current with an increase in the interior region of the molecular wire (cf. Eqs. (1) and (4)), the physical justification of its applicability for the analysis of current-voltage characteristics meets noticeable difficulties. This refers to the specification of both the pre-exponential factor $I_{c}$, Eq. (1), and especially the attenuation coefficient $\beta$, Eq. (3).

It is known that the ohmic regime is valid up to $V \cong(0.2-0.4) V$ [8, 19]. Therefore, in accordance with the inequality (2), the height of the barrier should be several eV. Meanwhile, the experiment shows that the value $\Delta E$ is about $1 \mathrm{eV}$ (chain with saturated bonds [8,20]) and less than $0.5 \mathrm{eV}$ (chain with conjugated bonds [21]), which does not correspond to the inequality (2). A problem also exists with determining the effective tunnelling mass $m^{*}$ for a finite chain.

\subsection{McConnell's Superexchange Model}

McConnell has suggested that because of overlapping MOs of neighbouring units in the donor-chain-acceptor structure (see Fig. 2, a), a distant superexchange coupling arises between the donor and the acceptor [13]. This opens the way for coherent electron transfer between spaced redox centres. In the superexchange mechanism of electron transfer, the chain connecting the donor and the acceptor acts as a bridge. This means that the bridge orbitals participate in a virtual way, playing the role of a mediator. According to McConnell model, the value of the superexchange donor-acceptor coupling decreases exponentially with an increase in the number of bridging chain units. As for the LWR junction, the role of the donor and acceptor belongs to the electrodes, and the molecular wire serves as a mediator of electron transfer. The interelectrode tunnelling current shows an exponential drop with increasing of the number $N$ of repeating chain units [14]. It can be shown that in the ohmic regime of the tunnelling charge transmission, the expression for the current has the form

$$
I=I_{M C} e^{-\beta_{N^{N}}}(N \geq 2) .
$$

Here, the attenuation factor (per chain unit) reads 

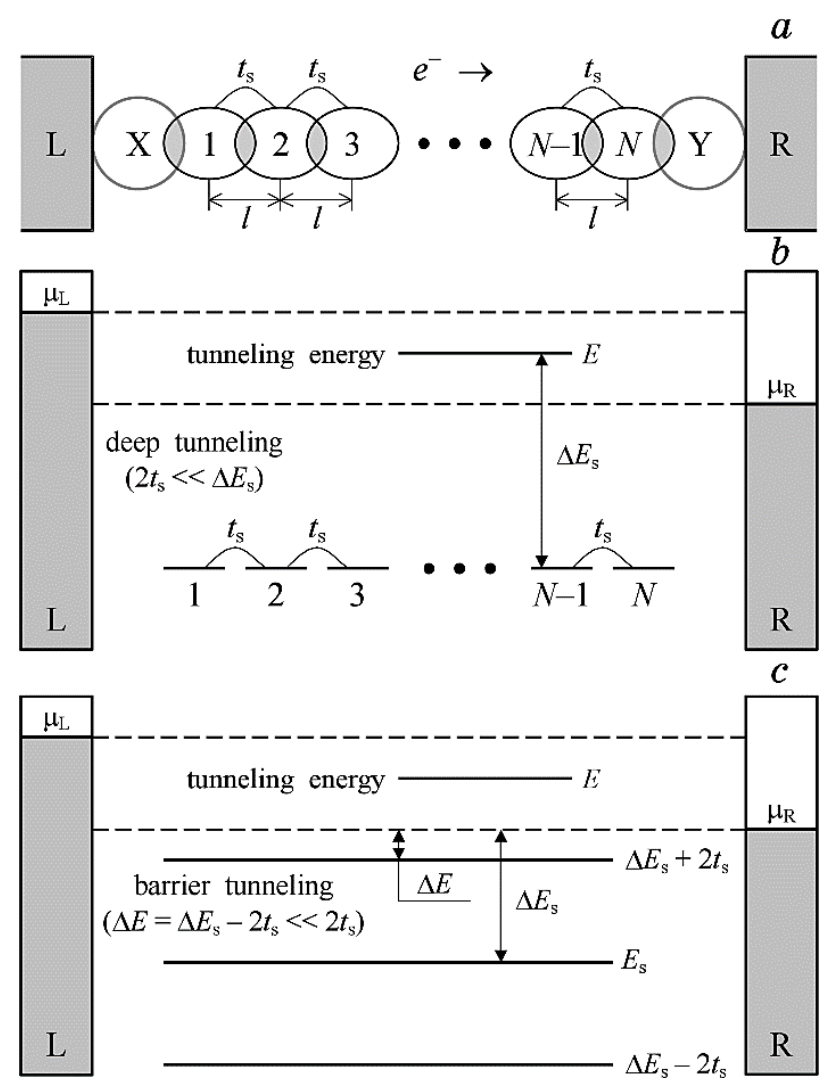

Fig. 2. The formation of the main superexchange-tunnelling pathway is due to the overlap of molecular orbitals localized on the structure units of the wire, as well as the overlap between terminal orbitals and surface atomic orbitals belonging to adjacent electrodes (a). Principal transmission gap $\Delta E_{s}$ at strong localization (b) and strong delocalization (c) of molecular chain orbitals. An apparent rectangular barrier appears with strong delocalization $(c)$.

$$
\beta_{N}=\beta_{M C}=2 \ln \left(\Delta E_{s} / t_{s}\right),
$$

where $\Delta E_{s}$ and $t_{s}$ are the key parameters of the superexchange model. The first parameter is associated with the transmission gap, which is defined as $\Delta E_{s}=E_{F}-E_{s}>0\left(\Delta E_{s}=E_{s}-E_{F}>0\right)$ for the hole (electron) tunnelling. Physically, the $\Delta E$ corresponds to the energy distance between the position of the Fermi level of the electrode, $E_{F}$, and the position of the localized orbitals of the identical chain units, $E_{s}=E_{1}=E_{2}=\ldots=E_{N}$, which are involved in the formation of superexchange coupling (Fig. 2,b). Typically, these frontier orbitals are HOMO or LUMO (highest occupied or lowest unoccupied orbitals, re- 
spectively). The $t_{s}$ parameter characterizes the coupling between the neighbouring chain orbitals noted above. The pre-exponential factor

$$
I_{M C}=V g_{0}\left(\Gamma_{L} \Gamma_{R} / t_{s}^{2}\right),
$$

where $g_{0}=e^{2} /(\pi \hbar) \approx 77.4 \mu \mathrm{S}$ is the unity conductance, contains quantities $\Gamma_{L}$ and $\Gamma_{R}$, which are the broadening of the energy levels of the chain edge units. The broadenings are caused by the interaction of these units with the corresponding adjacent electrodes $L$ and $R$. If $l$ (in $\AA$ ) is the wide size of structure unit of the chain, then the tunnelling width is $d=N l$. Comparing the expressions (1) and (6), one can set $I_{c}=I_{M C}$ and

$$
\beta=\beta_{N} l^{-1} \text {. }
$$

The advantage of the superexchange model is that the parameters used in it are directly related to the structural and energy characteristics of the molecular junction and, thus, have a clear physical meaning.

\subsection{Modified Superexchange Model}

The difference between the modified superexchange model and the standard (McConnell's) model is the absence of restrictions on its key parameters $\Delta E_{s}$ and $t_{s}$. As a result, instead of expression (7), the unbiased attenuation factor is obtained in the form [22, 23]

$$
\beta_{N}=\beta_{M D}=2 \ln \left[\Delta E_{s} / 2 t_{s}+\sqrt{\left(\Delta E_{s} / 2 t_{s}\right)^{2}-1}\right] .
$$

As for the tunnelling current (in ohmic regime), according to recent results $[17,18]$, it reads

$$
I=I_{M D} \Phi\left(\beta_{N}, N\right) .
$$

Here,

$$
\Phi\left(\beta_{N}, N\right)=\frac{\sinh ^{2} \beta_{N}}{\sinh ^{2}\left[(N+1) \beta_{N} / 2\right]}
$$

is the attenuation function, while

$$
I_{M D}=V g_{0}\left(\Gamma_{L} \Gamma_{R} / \Delta E_{s}^{2}\right)
$$

is the tunnelling current mediated by a single bridging unit. (Note that $\left.\Phi\left(\beta_{N}, 1\right)=1.\right)$ 


\section{RESULTS AND DISCUSSION}

The main goal of the work is to compare analytical expressions describing the tunnelling current-voltage characteristics in the framework of the most popular physical models. To do this, we consider the limiting cases resulting from the modified superexchange model. For this, we consider two types of the chains.

\subsection{Chain with Repeating One-Site Units}

For such type of chains ( $c f$. Fig. 3, $a$ ), the attenuation factors are given by the expressions (3), (7) and (10) for the barrier, standard superexchange and modified superexchange models, respectively. Let us take into account the fact that, subject to inequalities

$$
\Delta E=\Delta E_{s}-2 t_{s} \ll 2 t_{s}
$$

and

$$
\left(\Delta E_{s} / t_{s}\right)^{2} \gg 1,
$$

expression (10) has the following limit values,

$$
\beta_{M D}=\left\{\begin{array}{cc}
\beta_{B R} l \text { if } & \left(\Delta E / 2 t_{s}\right) \ll 1, \\
\beta_{M C} \text { if } & \left(\Delta E_{s} / 2 t_{s}\right)^{2} \gg 1 .
\end{array}\right.
$$
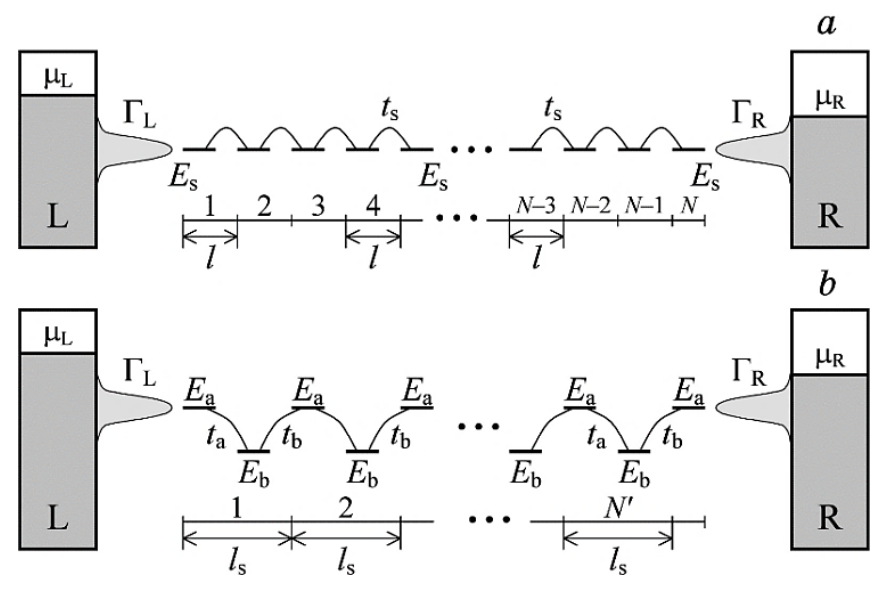

Fig. 3. Geometric and energy position of the chain with repeating one-site ( $a$ ) and two-site $(b)$ structure units. On site energies and intersite couplings are denoted via $E_{s}, E_{a(b)}$ and $t_{s}, t_{a(b)}$, respectively. Coupling to the electrodes are concentrated in the width parameters $\Gamma_{L}$ and $\Gamma_{R}$. 
It can be seen that the attenuation factors in both the Simmons barrier and the McConnell superexchange models are particular cases arising from the modified superexchange model. Thus, the inequalities (14) and (15) establish the limits of applicability of these models and their physical meaning. In particular, the McConnell model reflects the deep tunnelling process. As for the use of a rectangular barrier model, this makes sense only under specific condition (14), when the barrier height corresponds to gap $\Delta E=\Delta E_{s}-2 t_{s}$ (cf. definition in Eq. (14) and Fig. 2, $c)$. In this case, the effective mass is determined by the expression $m^{*}=\hbar^{2} / 2 t_{s} l^{2}$ containing the key superexchange parameter $t_{s}$ and the distance between neighbouring chain units $l$ ( $c f$. Figs. 2 and 3).

\subsection{Chain with Repeating Two-Site Units}

Fundamental difference between this chain and a chain with repeating single-site units is the presence of two types of localized frontier MOs having energies $E_{a}$ and $E_{b}$, and two types of intra-chain couplings, $t_{a}$ and $t_{b}(c f$. Fig. $3, b)$. For definiteness, we will assume that contact with the electrodes is through sites $a$. In this case, the modified superexchange model leads to the following expression for the ohmic tunnelling current,

$$
I=V g_{0} \frac{\Gamma_{L} \Gamma_{R}}{\Delta E_{a}^{2}} T_{\text {chain }}\left(E_{F}, N^{\prime}\right) .
$$

The decrease in current with an increase in the number of two-site chain units $N^{\prime}$ is presented in chain transmission function

$$
T_{\text {chain }}\left(E_{F}, N^{\prime}\right)=\frac{\sinh ^{2}(\Lambda / 2)}{\sinh ^{2}\left[\left(N^{\prime}+1\right) \Lambda / 2\right]} .
$$

The corresponding attenuation factor (per one two-site unit),

$$
\Lambda=2 \ln \left(\alpha+\sqrt{\alpha^{2}-1}\right),
$$

is controlled by the ratio

$$
\alpha=\frac{\Delta E_{a} \Delta E_{b}-t_{a}^{2}-t_{b}^{2}}{2 t_{a} t_{b}}>0
$$

that includes two pairs of key superexchange parameters: the zero-bias transmission gaps $\Delta E_{a(b)}=E_{F}-E_{a(b)}$ and the intersite couplings $t_{a(b)}$. It is easy to see that when converting a chain with two-site units into a chain with one-site units, i.e., at $t_{a}=t_{b}=t_{s}, E_{a}=E_{b}=E_{s}$ and $N=2 N^{\prime}+1$ (cf. Figs. $3, a, b$ ), we get the above results for the tunnel- 
ling current, i.e., the expressions (11) and (12). In particular, the relationship between attenuation factors looks like $\Lambda=2 \beta_{M D}$.

Consideration of limiting cases for the attenuation factor (19) shows that

$$
\Lambda=\left\{\begin{array}{cr}
\Lambda_{B R} l_{s}=(2 / \hbar) \sqrt{2 m_{\text {eff }}^{*} \Delta E} \quad \text { if }\left(\Delta E / t_{\text {eff }}\right)^{2} \ll 1, \\
\Lambda_{M C}=4 \ln \left(\Delta E_{a} \Delta E_{b} / t_{a} t_{b}\right) & \text { if } \Delta E_{a} \Delta E_{b} /\left(t_{a}+t_{b}\right)^{2} \gg 1 .
\end{array}\right.
$$

Here, $\Lambda_{B R}$ and $\Lambda_{M C}$ are the attenuation factors in the barrier and standard superexchange models. The parameters of the barrier model are defined as $\Delta E=E_{F}-E_{H}$ and $m_{e f f}^{*}=\hbar^{2} / 2 t_{e f f} l_{s}^{2}$ where

$$
E_{H}=(1 / 2)\left[E_{a}+E_{b}+\sqrt{\left(E_{a}-E_{b}\right)^{2}+4\left(t_{a}+t_{b}\right)^{2}}\right]
$$

and

$$
t_{\text {eff }}=t_{a} t_{b} / \sqrt{\left(E_{a}-E_{b}\right)^{2}+4\left(t_{a}+t_{b}\right)^{2}}
$$

are the energy of the delocalized HOMO of the chain and the apparent interunit coupling, respectively.

Note that, for both types of chains, the attenuation factors $\beta_{N}$ and $\Lambda$ have a similar analytical form. Therefore, presented in Fig. 4, the relationship between $\Delta E_{s} /\left(2 t_{s}\right)$ and $\beta_{N}$ will be identical for the relationship between $\alpha$ and $\Lambda$. It can be seen from the Fig. 4 that the barrier model

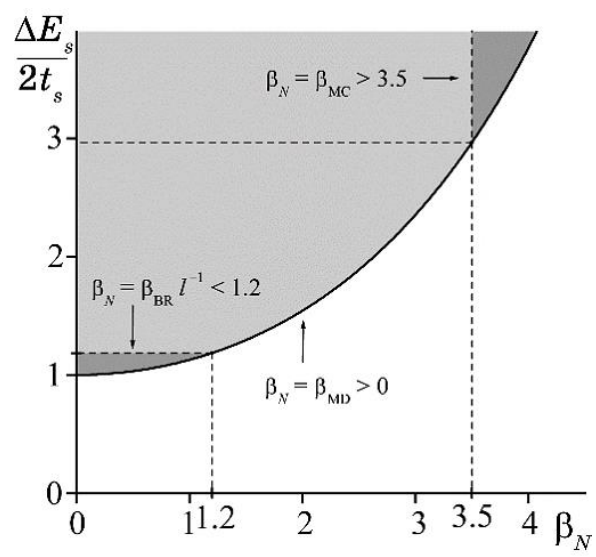

Fig. 4. The areas, in which barrier and standard superexchange models can work, are determined by the conditions $\beta_{N}<1.2$ and $\beta>3.5$, respectively. The modified superexchange model can be used to analyse the tunnelling current in the region $\beta_{N}>0$ covering both of the above areas. 
leads to results similar to those that follow from the modified superexchange model, if $0<\beta_{N}<1.2$.

For standard superexchange models, a similar result is achieved at $\beta_{N}>3.5$. This is reflected in Fig. 5 , where the exponential dependence of the normalized tunnelling current across the chain of repeating single-site units, $\xi=\xi(N)$, is shown. It can be seen (Fig. 5, a) that, for the chain, where $\Delta E_{s} \approx 3 \mathrm{eV}, t_{s} \approx 0.4 \mathrm{eV}$ and, thus, $\beta_{N} \approx 4$, the standard superexchange model leads to the same results as the modified superex-
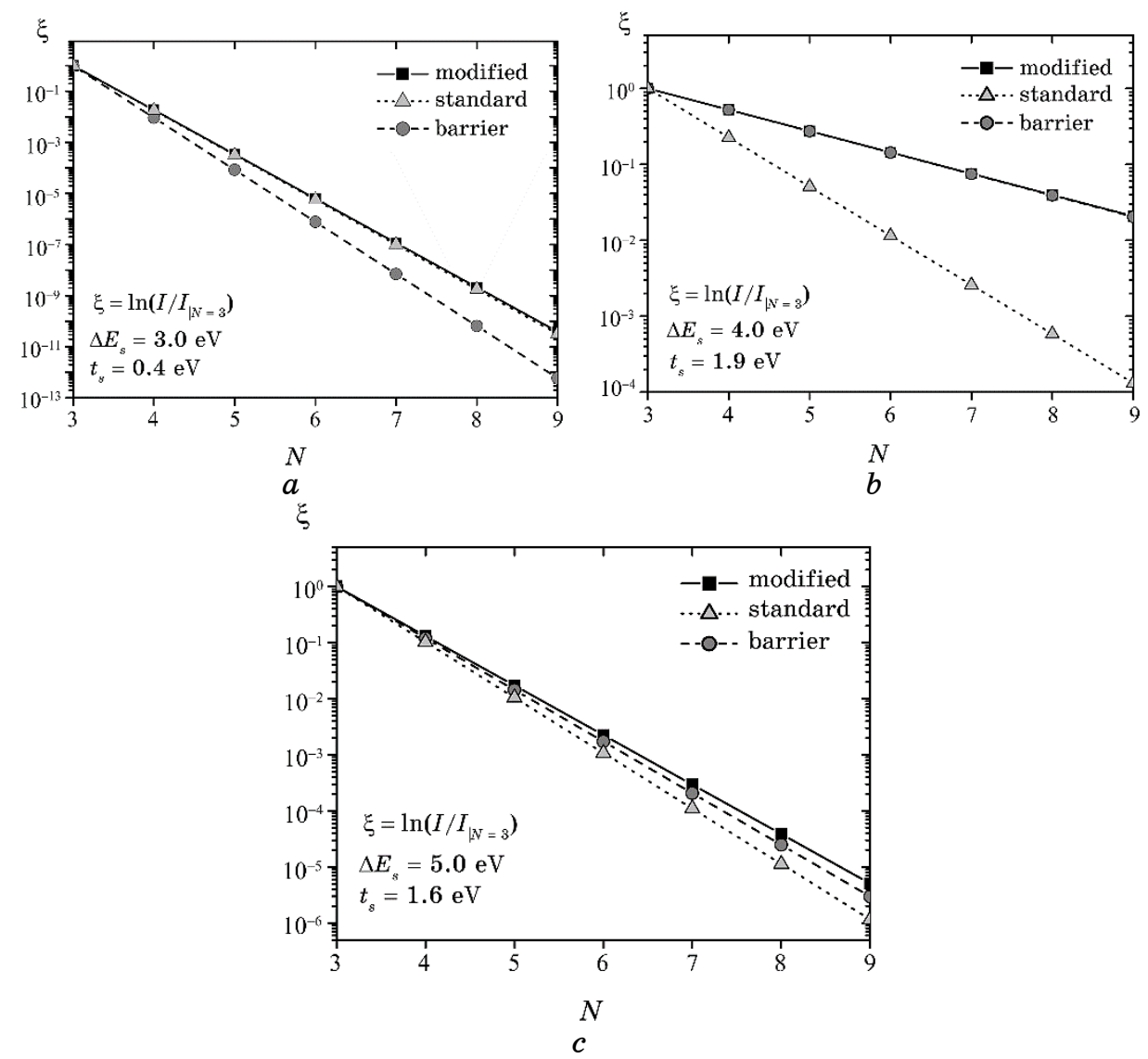

Fig. 5. The exponential decrease in the tunnelling current through the molecular wire, described in terms of modified and standard superexchange models, as well as the barrier model. There is no match between the barrier and standard superexchange models. Calculation of the value $\xi=I / I_{\mid N=3}=\exp \left[\left(-\beta_{N}\right)(N-3)\right]$, in which the attenuation factor $\beta_{N}$ is given by the barrier model, Eq. (3), the standard superexchange model, Eq. (7) and the modified superexchange model, Eq. (10). 
change model. This means that for bridging chains, where the unit-tounit couplings are weak, a deep tunnelling regime is realized. For parameters $\Delta E_{s} \approx 4 \mathrm{eV}, t_{s} \approx 1.9 \mathrm{eV}$, when $\beta_{N} \approx 0.7$, there is a coincidence of the results presented by the barrier and the modified superexchange models (Fig. 5, b). This is due to the fact that, for such key superexchange parameters, the height of the apparent tunnelling barrier is rather small ( $\Delta E \approx 0.2 \mathrm{eV}$ ) and, therefore, the approximation (14) is true. At the same time, if $\Delta E_{s} \approx 5 \mathrm{eV}, t_{s} \approx 1.6 \mathrm{eV}$, then $\beta_{N} \approx 3.12$. With this attenuation factor, the results of both the barrier and standard superexchange models differ from the results following from a more rigorous modified superexchange model (compare the Figs. 4 and 5,c).

\section{CONCLUSIONS}

In the present work, a comparison is made of the physical models used to analyse the ohmic current-voltage characteristics of molecular wires. Although simple analytical expressions obtained in the framework of the Simmons barrier model or the McConnell superexchange model lead to an exponential decrease in the tunnelling current with increasing wire length, the application of each model, as we have shown, is limited by conditions (14) and (15). This can also be clearly seen from Figs. 4 and 5. A more complete description is given by the modified superexchange model, in which the restrictions on the relation between the key parameters $\Delta E_{s}$ and $t_{s}$ are removed. The absence of these restrictions allowed us to consider the limiting cases of the formation of a tunnel transmission and show that the barrier and standard superexchange models act as particular manifestations of tunnelling through bridging chains. In this case, the transmission simulates tunnelling through a rectangular barrier when the HOMO level of the chain is close to the Fermi level of the electrode (see condition (14)). Otherwise, that is realized with a weak coupling between the units (see condition (15)), the transmission looks like deep tunnelling. It is important to note that the results obtained are valid for a chain with one-site units as well as for more complex chains, which are composed of two-site units. We also note the results related to the evaluation of the pre-exponential factor $I_{c}(1)$, which characterizes the contact of the electrodes with the molecular wire. The widely used simple Simmons barrier model cannot be used for this purpose, because according to the Eq. (4), it leads to a nonphysical result in the limit $d \rightarrow 0$. The modified superexchange model shows that the tunnelling length dependence on $N$ covers the interior part of the wire, that is the minimum chain length is $N=1$ so $d_{\min }=l\left(l_{s}\right)$ (Figs. 2 and 3). Actually, however, the exponential dependence of the tunnelling current on $N$ is determined by the attenuation function $\Phi\left(\beta_{N}, N\right)$ (see Eqs. (11) and (12)). For instance, for $\beta_{N}=1$ one obtains $\Phi\left(\beta_{N}, N\right) \simeq \exp \left(-\beta_{N} N\right)$ for 
$N>2$ while, for $\beta_{N}=0.7$, the same behaviour is observed at $N>4$. This circumstance must be taken into account, when analysing the current-voltage characteristics of molecular wires.

\section{ACKNOWLEDGMENTS}

Author acknowledges the support by the N.A.S. of Ukraine via project 0116 U002067.

\section{REFERENCES}

1. A. Aviram and M. Ratner, Molecular Electronics: Science and Technology (New York: New York Academy of Sciences: 1998).

2. Introducing Molecular Electronics (Eds. G. Cuniberti, G. Fagas, and K. Richter) (Berlin: Springer: 2005).

3. J. C. Cuevas and E. Scheer, Molecular Electronics: an Introduction to Theory and Experiment. $2^{\text {nd }}$ Edition (Singapore: World Scientific: 2013).

4. $\quad$ R. M. Metzger, Chem. Rev., 115, No. 11: 5056 (2015); https://doi.org/10.1021/cr500459d.

5. L. Venkataraman, J. E. Klare, I. W. Tam, C. Nickolls, M. S. Hybertsen, and M. L. Steigerwald, Nano Letters, 6, No. 3: 458 (2006); https://doi.org/10.1021/nl052373+.

6. N. Koch, Chem. Phys. Chem., 8, No. 10: 1438 (2007); https://doi.org/10.1002/cphc.200700177.

7. D. Xiang, X. Wang, Ch. Jia, T. Lee, and X. Guo, Chem. Rev., 116, No. 7: 4318 (2016); https://doi.org/10.1021/acs.chemrev.5b00680.

8. V. B. Engelkes, J. M. Beebe, and C. D. Frisbie, J.Am. Chem. Soc., 126, No. 43: 14287 (2004); https://doi.org/10.1021/ja046274u.

9. F. C. Simeone, H. J. Yoon, M. M. Thuo, J. R. Barber, B. Smith, and G. M. Whitesides, J.Am.Chem. Soc., 135, No. 48: 18131 (2013); https://doi.org/10.1021/ja408652h.

10. E. Wierzbinski, X. Yin, K. Werling, and D. H. Waldeck, J. Phys. Chem. B, 117, No. 16: 4431 (2013); https://doi.org/10.1021/jp307902v.

11. M. Baghbanzadeh, C. M. Bowers, D. Rappoport, T. Zaba, L. Yuan, K. Kang, K.-C. Liao, M. Gonidec, P. Rothemund, P. Cyganik, A. Aspuru-Guzik, and G. M. Whitesides, J.Am. Chem.Soc., 139, No. 22: 7624 (2017); https://doi.org/10.1021/jacs.7b02770.

12. J. G. Simmons, J.Appl. Phys., 34, No. 6: 1793 (1963); https://doi.org/10.1063/1.1702682.

13. H. M. McConnel, J. Phys. Chem., 35, No. 2: 508 (1961); https://doi.org/10.1063/1.1731961.

14. M. A. Rampi and G. M. Whitesides, Chem. Phys., 281, Nos. 2-3: 373 (2002); https://doi.org/10.1016/S0301-0104(02)00445-7.

15. J. Jortner, M. Bixon, A. A. Voityuk, and N. Rösh, J. Phys. Chem., 106, No. 33: 7599 (2002); https://doi.org/10.1021/jp014232b.

16. E. G. Petrov, Ya. R. Zelinskyy. V. May, and P. Hänggi, J.Chem. Phys., 127: 084709 (2007); https: / /doi.org/10.1063/1.2768521. 
17. E. G. Petrov, JETP Lett., 108, No. 5: 302 (2018); https://doi.org/10.1134/S0021364018170101.

18. G. Petrov, Phys. Status Solidi B, 256, No. 11: 1900092 (2019); https://doi.org/10.1002/pssb.201900092.

19. F. Chen, X. Li, J. Hihath, Z. Huang, and N. Tao, J.Am. Chem. Soc., 128, No. 49: 15874 (2006); https://doi.org/10.1021/ja065864k.

20. X. D. Cui, A. Primak, X. Zarate, J. Tomfohr, O. F. Sankey, A. L. Moore, T. A. Moore, D. Gust, L. A. Nagahara, and S. M. Lindsay, J. Phys. Chem. B, 106, No. 34: 8609 (2002); https://doi.org/10.1021/jp0206065.

21. Y. Zang, S. Ray, E.-D. Fung, A. Borges, M. H. Gartner, M. L. Steigerwald, G. Solomon, S. Patil, and L. Venkataman, J.Am.Chem. Soc., 140, No. 41: 13167 (2018); https://doi.org/10.1021/jacs.8b06964.

22. V. Mujica, M. Kemp, and M. Ratner, J.Chem. Phys., 101, No. 8: 6856 (1994); https://doi.org/10.1063/1.468315.

23. E. G. Petrov, I. S. Tolokh, A. A. Demidenko, and V. V. Gorbach, Chem. Phys., 193, No. 3: 237 (1995); https://doi.org/10.1016/0301-0104(95)00426-O. 